УДК 37.013

DOI: 10.31453/kdu.ru.978-5-7913-1143-6-2020-214-232

Мальсагова Марьям Хаматхановна, кандидат педагогических наук, преподаватель ФГБОУ ВО «Ингушский государственный университет»

Иванов Павел Викторович, аспирант ФГБОУ ВО «Ингушский государственный университет»

Malsagova Maryam Khamatkhanovna $\mathrm{PhD}$, Senior teacher "Ingush state university"

Ivanov Pavel Viktorovitch

Graduate student, "Ingush state university"

\title{
НЕЙРОПСИХОЛОГИЧЕСКАЯ ТЕХНОЛОГИЯ ОБУЧЕНИЯ МОЛОДЕЖИ И ВЗРОСЛЫХ
}

\section{NEUROPSYCHOLOGICAL TECHNOLOGY OF TEACHING YOUTH AND ADULTS}

\begin{abstract}
Аннотация. В предлагаемой психолого-педагогической общественности статье изложены возрастные нейродидактические особенности взрослых обучающихся, эмпирические положения нейродидактики взрослых. Определена композиционная основа авторской технологии. Рассмотрены познавательные процессы обучения: ощущения, восприятие, воображение, внимание, память, речь, мышление. Выполнена нейродидактическая характеристика знаний, их организации в долговременной памяти. Изложены закономерности процесса запоминания. Обоснованы содержание, принципы обучения взрослых. Разработана модель нейродидактики взрослых, даны комментарии ее этапам: мотивирующему, диагностическому, учебно-развивающему, методическому, контролирующему.
\end{abstract}

Annotation. The article proposed to the psychological and pedagogical community describes the age-related neurodidactic features of adult students, as well as the empirical provisions of adult neurodidactics. The compositional basis of the author's technology is defined. The cognitive processes of learning are considered: sensations, perception, imagination, attention, memory, speech, and thinking. The neuro-didactic characteristic of knowledge and its organization in long-term memory is performed. The regularities of the memorization process are described. The content and principles of adult education are substantiated. A model of adult neurodidactics has been developed 
and comments have been given on its stages: motivating, diagnostic, educational and developmental, methodological, and controlling

Ключевые слова. Нейродидактика, принципы обучения, молодежь, взрослые, нейродидактическая модель.

Keywords. Neurodidactics, teaching principles, youth, adults, neurodidactic model.

Концепция непрерывного образования, доминировавшая в 1990-начале 2000 гг. способствовала развитию нейродидактики взрослых. Из многих определений понятия «взрослый человек» нам импонирует данное М.Г. Ермолаевой, согласно которому это - «период жизни человека, наступающий после юности» [1, с. 20]. Его характеристиками являются: хронологический возраст, психофизическая и социальная зрелость, экономическая самостоятельность, гражданско-правовая дееспособность, вовлеченность в сферу профессионального труда.

К характеристикам «взрослого обучающегося» С.И. Змеёв [2, с.81-82] относит: 1) готовность к обучению для достижения цели и решения жизненно важных проблем, 2) стремление к самореализации, 3) жизненный опыт как источник обучения, 4) его детерминацию профессиональными, пространственно-временными, социально-культурными условиями.

Относительно возрастного этапа взрослости у ученых нет единого мнения: Ю.Н. Кулюткин называет период от 16 до 70 лет, Е.И. Степанова - от 18 до 40 лет, Д. Бромлей и Б.Г. Ананьев - от 21 до 65 лет, Д.И. Фельдштейн - от 21 до 75 лет, Дж. Биррен - от 17 до 75 лет, Э. Эриксон - от 20 лет до конца жизни. Размывание хронологических границ взрослости объясняется частым несоответствием биологического, календарного и социльного возраста. Мы придерживаемся ранее принятой возрастной классификации и относим к взрослым людей в возрасте от 24 лет.

Обобщенные А.А. Мальсаговым и В.В. Лезиной [3] эмпирические положения нейродидактики взрослых сводятся к следующему. Мозг взрослого обучающегося способен выполнять несколько функций одномоментно. Он единовременно собирает и разлагает воспринимаемую информацию, оперирует 
частью и целым. Анализ и синтез как в наивысшей степени значимые и взаимообусловленные процессы нуждаются в подкреплении соответствующими методами и приемами. В частности, ввод учебного материала на уроке целесообразно осуществлять в режиме анализа и синтеза, конкретизации и обобщения, индукции и дедукции. Мозг связывает прежний опыт с новой ситуацией. Ее понимание и осмысление детерминируется актуализацией имеющихся у обучающихся знаний и их использованием в познавательном процессе (зона актуального и ближайшего развития у Л.С.Выгоского). Жизненный опыт взрослых обучающихся оптимизирует этот процесс. Другим положительным моментом у данной категории обучающихся является закрепленный клишированный акт преодоления интеллектуальных трудностей и установления закономерностей. Характерной особенностью мозга является способность одновременного восприятия информации в условиях периферийного восприятия и сфокусированного внимания. Исходя из этого, направленное периферийное восприятие является конструктивным фактором обучения взрослых.

Одновременность протекания процессов сознания и подсознания в мозге обучающегося приводит к тому, что он получает избыточную информацию из факторов дидактической среды (жесты, мимика, пластика обучающего, атмосфера в аудитории, звук, освещение и др.). Такая природная организация восприятия мозгом информации нацелена на получение ее максимального количества и обеспечение ее достоверности. При этом мозг каждого обучающегося индивидуален в плане переработки информации, гибкости мыслительных процессов, доминантного вида памяти. Последняя располагает несколькими системами, в частности, визуально-пространственной и основанной на заучивании. Визуально-пространственная память в форме «пчелиных сот» системно заполняется информацией и быстро оттуда извлекается, однако с возрастом ослабевает. Заучивание достаточно трудоемко в запоминании и воспроизведении, однако компенсирует возрастную слабость визуально-пространственной памяти. 
Специфические черты высших психических функций взрослого обучающегося по А.Р. Лурии [4, с. 54] обладают сложной структурой (множество звеньев, многогранный характер взаимодействия), включают разные структуры функциональных систем, которые являются их онтогенетическими механизмами, демонстрируют динамический характер мозговой локализации (организации), изменчивость, пластичность и взаимозаменяемость звеньев, обнаруживают прямую зависимость от прижизненных условий формирования, возможность перестройки этих систем, отражают возрастные изменения состава афферентных и эфферентных звеньев, их взаимосвязь внутри функциональных систем.

Вместе с тем возраст не является причиной их расстройства и затруднения в обучении, что убедительно доказывается в диссертации А.А. Мальсагова «Нейродидактика взрослых» (Махачкала: ДГУ, 2016, 167 с.). Наличие потребностей и мотивации (стремление к финансовому благополучию, высокому статусу, признанию в кругу близких людей и обществе и др.) у взрослых обучающихся обеспечивает беспрепятственную интериоризацию внешнего (социального) побуждения к формированию компетенции во внутреннее. Сенсорные и моторные процессы воплощаются в автоматизированные умственные действия. Последние объединяют уже сформированный ранее алгоритмический путь реализации таких действий и их перестройку. Автоматизированные действия и мотив обучения обеспечивают его эффективность.

Стимулами качества обучения выступают общение, творчество, социально ориентированное поведение. Последнее фокусируется на семье, коллективе, планировании будущего, образовании, прогнозировании результатов труда, искусстве, культуре, экономике, политике и др. Обучение как энергоемкий физиологический процесс зависимо от сбалансированного питания, научной организации труда, гигиены.

Анатомические гендерные особенности мозга различны: у женщин вес мозолистого тела (пучка волокон между левым и правым полушарием) больше, 
чем у мужчин. В связи с этим, обмен информацией между полушариями у них протекает интенсивнее. Одновременная работа обоих полушарий у женщины приводит к более успешному мыслеформулированию и коммуникации, чем у мужчин. У последних за вербальную деятельность отвечает левое полушарие, правое же ответственно за решение абстрактных проблем. В итоге мужское пространственное мышление опережает женское. В вопросе гендерных типов мышления существенную роль выполняют генетические факторы и гормоны. Возрастные изменения приводят к сдвигам гормонального фона: люди после 50 лет начинают отчасти думать как представители противоположного пола.

В процессе обучения взрослых важную роль выполняет эмоциональный интеллект (EQ), значимость которого сопоставима с IQ. Эмоции являются сложными психологическими образованиями с отражательными (познавательными) и регуляторными функциями. Они основываются на многообразных потребностях и включены в разные виды психической деятельности. Воздействующие на организм внешние стимулы, по утверждению У. Джеймса и К. Ланге, вызывают вегетативные, вазомоторные и нервномышечные изменения. Переработка центральной нервной системой импульсов от органов движения и внутренних органов, изменений в организме, приводит к возникновению эмоций. Таким образом,с позиции деятельностного подхода (А.Н.Леонтьев, В.К.Вилюнас, О.К.Тихомиров и др.),эмоции представляют собой внутренние регуляторы деятельности. По мнению А.Н.Леонтьева, эмоции отражаютотношения между мотивами и соответствующей им деятельностью [5, c.45].Ее регуляторами являются «значимые переживания», они отражают ее личностный смысл. Это утверждение в полной мере иллюстрирует процесс обучения взрослых.

Эмоции инициируют познавательную деятельность, они же регулируют, контролируют ее осуществление с помощью механизма оценки в соответствии с изначальной потребностью. Общие положения о единстве эмоций и познания сформулированы Л.С. Выготским [6, с. 121], В.К. Вилюнасом [7, с. 67 - 68], С.Л. Рубинштейном [8, с.78] и др. Как отражение мотивов и результатов учебной 
деятельности эмоции либо неосознаваемы, либо частично осознаваемы. Когнитивная самооценка эмоций направлена на коррекцию собственных личностных качеств в процессе познания.

Эмоционально-личностные психические явления, как и познавательные процессы, обладают системной организацией и развиваются под воздействием культурно-исторических факторов. В связи с этим, Л.С. Выготский отмечал наличие тесной связи между эмоциональными и познавательными процессами (связь «интеллекта с аффектом»). Это находит воплощение в виде «интеллектуализации» эмоций в процессе общественно-исторического развития человека и в онтогенезе [9, с. 45]. Процесс «интеллектуализации» эмоций дополнен Л.И. Божович [10, с. 90] их «волюнтаризацией». Последняя направлена на обращение волевым решением обучающегося элементарных эмоций в высшие. Из этого вытекают рекомендации в области эмоционально-личностных аспектов обучения взрослых. Они включают инициирование и регулирование познавательной деятельности обучающихся эмоциями, системную организацию их эмоционально-личностных проявлений.

В вопросе латеральных особенностей взрослых обучающихся отметим то обстоятельство, что межполушарная асимметрия мозга у взрослого человека варьирует от усложнения и совершенствования механизмов межполушарного взаимодействия в молодом и зрелом возрасте до ее сниженных показателей в старости. Эффективным методом развития правого полушария головного мозга является тренинг М. Зденек [11, с.88], основанный на соединении методик психологической направленности и восточных философско-религиозных учений. Психологические тренинги буддизма, дзень-буддизма, чань-буддизма, йоги, даосизма эффективны в развитии правого полушария головного мозга. Так, медитация обучает концентрации внимания и релаксации, развитию спонтанного мышления и интуиции. Для «отключения» левого полушария, препятствующего внутренней сосредоточенности на себе, используются мандалы. 
Другим методом поддержания межполушарного взаимодействия является учет сенсорно-перцептивной организации опыта (модальности внутреннего опыта). Взрослые люди, как правило, обнаруживают определенный доминирующий тип модальности: визуальной, аудиальной, кинестетической. Визуальная модальность, детерминированная зрительной памятью, заключает внутренний опыт «визуалов», связанный с запоминанием, сохранением и воспроизведением зрительных образов. Таких взрослых обучающихся большинство. Аудиальная модальность, обеспечиваемая слуховой памятью, заключает внутренний опыт «аудиалов», связанный со звуками и звучащей речью. Кинестетическая модальность, связанная с движением и осязанием «кинестетиков», определяется двигательной, осязательной, обонятельной и вкусовой памятью. Нейродидактикой приветствуется мультимодальный подход к обучению взрослых, предполагающий учет каждой доминантной модальности.

Названный подход учитывает не только доминантную модальность, но и тип темперамента взрослых обучающихся (активность, моторику, эмоциональность, импульсивность), индивидуальную динамику развития психических процессов (мышление, произвольное внимание, воображение, память, речь, волю, эмоции). В их совокупности они обеспечивают познавательную, творческую деятельность обучающихся, их речь, саморегуляцию, коммуникацию.

Отдельный контингент взрослых обучающихся составляют пожилые люди. В связи с тем, что их высшие психические функции замедляются, развитие когнитивной сферы данной категории людей должно быть поддерживающим, т.е. включающим специальные методы, формы, техники и технологии. Основу такого обучения составляет личностно-центрированный подход, состоящий в доверии человеческой природе и способности ее саморазвития. Последнее обеспечивается уникальной биологической системой - мозгом. Поддерживающее обучение предназначено для функционирования существующей системы образа жизни и деятельности человека, решения им ежедневных проблем. 
Продуктивность сотрудничества взрослых обучающихся и педагога обеспечивается вместе с тем индивидуальными мыслительными особенностями обоих. Так, правополушарные конформные обучающиеся проявляют склонность к эмоциональным, внушающим воздействиям, a левополушарные «рационалисты» - к убеждающим, рациональным методам. Педагогу следует учитывать то обстоятельство, что профессионально гуманитарно ориентированные представители левополушарного когнитивного типа нередко избегают работы с наглядными материалами (математические формулы, графики, чертежи, диаграммы, символические изображения, схемы), предпочитая им словесные описания и объяснения. Даже восприятие произведений искусства сопряжено у них с речевым комментарием, что характеризует их как аудиалов. Напротив, представители правополушарного когнитивного типа не являются риторами, но с успехом оперируют образами в художественной деятельности.

Вышеизложенное составляет теоретическо-эмпирическое обеспечение нейродидактики взрослых. За композиционную основу разрабатываемой нами технологии мы взяли разработанную А.А. Мальсаговым нейродидактическую технологию обучения взрослых. Ее компоненты включают: 1) замысел обучения: потребность, неосознанное и осознанное побуждение, переживание, целеустановку, мотивы, субъективный опыт, 2) формирование содержания обучения, 3) создание программы обучения, 4) разработку и реализацию учебного процесса, 5) технологические приемы обучения: принципы, методы, формы, средства, 6) контроль, представленный промежуточной и итоговой диагностикой компетенций. Значимое место в технологии А.А.Мальсагова отведено мотиву, побуждающему современного взрослого человека включиться в образовательную деятельность. В нейродидактическом обучении взрослых автор делает акцент на доминанту утилитарных потребностей в сознании взрослого человека и личностно значимой конструктивной деятельности, ее социально-профессиональной направленности. Другим важным звеном, побуждающим к учению и активизирующим высшие психические функции 
взрослых обучающихся является их субъективный опыт. Должное внимание уделено эмоциям, стимулирующим мозговую активность. В рамках всего учебного процесса осуществляется диагностика когнитивных характеристик взрослых обучающихся выясняется активность их мозговых процессов.

Для нашей технологии важность представляют развиваемые нейродидактикой познавательные процессы обучающихся: ощущения, восприятие, воображение, внимание, память, речь, мышление. Их специфика в обучении взрослых состоит в следующем.

Ощущения (внешние, внутренние, двигательные) как осознаваемый или неосознаваемый продукт переработки центральной нервной системой значимых раздражителей со временем приобретают узнаваемые, клишированные формы. Многократно испытанное ощущение быстрее распознается нервной системой, увеличивается скорость ответной реакции мозга. Неизменными остаются общие законы функционирования ощущений: чувствительность, адаптация, контрастность (изменение чувствительности, обусловленное предшествующим раздражителем).

Восприятие как процесс приема и переработки информации, поступающей в мозг через органы чувств, обретает во взрослом возрасте приоритетные виды, детерминированные образом жизни и родом деятельности человека. В урбанистических культурах у взрослых людей развиты зрение, слух и вкус, в сельско- и натуральнохозяйственных культурах эти виды дополняются хорошо развитыми осязанием, кинестезией, обонянием. Специфична палитра сформированных сознанием и являющихся отражением внутреннего мира человека образов, которыми оперируют его память, мышление, внимание, эмоции. Уникальность и эмоциональная окрашенность образов складывается из потребностей и мотивов, установок, интересов взрослого обучающегося.

Сформированными и прочно закрепленными характеристиками восприятия в процессе обучения у взрослой аудитории являются: предметность (обособленность физического тела в пространстве и времени), целостность (синкретизм частей и целого в образе), константность (относительная 
независимость образа от условий восприятия, в частности, неизменными остаются форма, цвет, размер), обобщенность (соотнесенность образа с определенным названным классом объектов).

Воображение как психический процесс создания образов на основе прошлых восприятий носит у взрослых преимущественно произвольный (активный) характер, тогда как у детей оно по преимуществу непроизвольное (пассивное). Произвольное воображение детерминируется формированием внутреннего плана действий, планированием и программированием деятельности, регулированием эмоциональных состояний.

Внимание как активная направленность сознания человека на определенные свойства и явления действительности при отвлечении от несущественного характеризуется у взрослых произвольностью (сознательным регулированием) и послепроизвольностью (постсознательным регулированием, не требующим усилий). Превалирование внешних раздражителей (интенсивность, частота сигналов внешнего поля) в детской аудитории сменяется внутренними (заинтересованность и потребность в информации, ее актуальность, эмоциональное состояние, значимость сигнала, периферическая настройка органов чувств: присматривание, прислушивание) у взрослых. У них легче достигаются концентрация, устойчивость, переключаемость, распределение, предметность.

Память как процесс запечатления и воспроизведения взрослым обучающимся его опыта в результате сохранения, воспроизведения и переработки информации характеризуется во взрослой аудитории устойчивостью сформированных прижизненно видов памяти: образной, символической (словесной и логической), двигательной, эмоциональной. Возрастная стагнация генетической памяти (скорость, объем, точность, длительность) компенсируется интересом, потребностью, мотивацией запоминания.

Речь как фактор, формирующий архитектонику мышления и организующий структуру восприятия, характеризуется у взрослых развитостью. 
Достигают высоких показателей все ее виды: внутренняя, устная, письменная, активная, пассивная. В условиях взрослой аудитории к речи предъявляются следующие требования: владение терминологией, ясность, аргументированность, убедительность, логичность, предметность, четкость, академичность, голосовое, произносительно, темповое оформление.

Мышление со свойственными ему понятиями, суждениями, умозаключениями, представлениями и операциями (анализ, синтез, конкретизация, абстрагирование, обобщение, сравнение, классификация) ориентировано у большинства взрослых обучающихся на его практический вид. (Другими видами мышления являются конкретно - образное (художественное) и абстрактное (словесно-логическое). Практическое мышление подчинено решению конкретных задач в рамках конструктивной, организаторской, производственной деятельности. У взрослого контингента обучающихся ярко проявляются наблюдательность, детализирование, ситуативность, пространственное видение, реактивность, волевые устремления, глубина, широта, гибкость, скорость, самостоятельность, критичность. В основе обучения взрослых - развитие личности и ее познавательных способностей: учебной мотивации, социальных и профессиональных качеств.

Способность к обучению взрослого субъекта определяется его интеллектом и свойственными ему умственными потенциями: счетной способностью, вербальными (словесными) гибкостью и восприятием, пространственной ориентацией, памятью, способностью к рассуждению, скоростью восприятия сходства или различий между предметами и изображениями (Л.Л.Терстоун [12, р.304 - 305]). Эта классификация была дополнена И.П. Гилфордом, который выделил 120 факторов интеллекта [13, p.75]. Коэффициент интеллектуальности IQ в его среднем значении соответствует 100 баллам, в низком убывает, в высоком возрастает до показателя 200 баллов. Обычное отклонение составляет 16 баллов. Основная масса взрослых обучающихся (около 70\% \%) демонстрирует средний интеллект [13, p.81]. В обучении наиболее ценны следующие интеллектуальные характеристики 
взрослых: скорость мыслительных реакций, пытливость, любознательность, гибкость, глубина, логичность, критичность. Напротив, стереотипность мышления, его инертность, табуированные препятствия (архаичные запреты и традиции) тормозят дидактический процесс. Он должен начинаться с педагогического наблюдения, анализа продуктов учебной деятельности обучающихся, беседы с ними, тестирования на уровень IQ, выявления общеобразовательных и профессиональных знаний.

С точки зрения нейродидактики «знания» - это информационнокогнитивные понятийные, образные, вербальные, семантические образования, связанные с аксиологическими (ценностными) приоритетами и сохраняющиеся в долговременной памяти для решения ситуативных задач (Определение наше). Когнитивисты (Т.Ю. Иванова и др.) различают знание явное (формализованное, выраженное вербально и цифрами) и неявное (интуитивное). Первое опосредовано рациональным, научным познанием, второе - интуитивным, религиозным. Если рациональное познание изучено в наши дни достаточно глубоко, то интуитивное - мало исследовано. Вместе с тем тысячелетняя история религиозного знания настаивает на важности постижения последнего.

В современном образовании многие аспекты учебной деятельности (интуиция, догадка, прозрение, идеалы, ценности) остаются за рамками учебного процесса. Они остаются за гранью подсознания. Вместе с тем человек воспринимает только 5-10\% информации из внешнего мира. Остальное подавляющее количество информации поступает в человеческий мозг в процессе апперцепции, т.е. не осознается. В связи с этим, важной нейродидактической идеей является максимальное расширение сферы сознания взрослых обучающихся, произвольной регуляции обучения. Этот вопрос непосредственно связан с работой долговременной памяти.

Ученые (С.В Маланов [14, с.288] и др.) полагают, что знания извлекаются из долговременной памяти в форме репрезентаций - концептуальных (категориальных) конструкций, выстраиваемых субъектом в определенном ситуативно детерминированном контексте для осуществления специальных 
целей. При этом основанные на значении концептуальные (категориальные) репрезентации выражают знания о мире с помощью предикативных структур языка. Базирующиеся на восприятии образные репрезентации отражают модальные и пространственные качества объектов и процессов: их расположение, размер, форму. Имеющие в своей основе действия, одноименные репрезентации действий включают средства, способы, последовательность исполнения действия, в языковом выражении коррелирующие с вопросами «чТо?» и «Как?».

Проблема организации и кодирования информации в долговременной памяти человека исследована достаточно полно, о чем свидетельствуют: культурно-историческая теория (Л.С. Выготский, А.Н. Леонтьев), гипотеза организующих связей (Г. Бауэр), теория (модель) двойного кодирования информации в долговременной памяти (А. Пэвио), теория (модель) определения концептов через совокупность свойств в организации семантических связей (А. Коллинз, М. Квиллиан), теория (модель) концептуальных прототипов в организации семантических связей (Э. Рош), теория (модель) семантической организации процедурных знаний (Пуатрено, Ришар, Тижюс), модель многомерного кодирования перцептивных признаков объектов (Д. Грин, А. Пуроит), модель организации понятий в форме пропозициональных сетей (Д. Андерсон, Г. Бауэр), модель организации семантических сетей «ELINOR», модели схемной организации когнитивных семантических структур, концептуально-пропозициональная гипотеза кодирования (Д. Андерсон, Г. Бауэр), гипотеза двойного кодирования (А. Пэвио), гипотеза функциональной эквивалентности внешних стимулов и процессов кодирования в мозге (Р. Шепард).

Квинтэссенцией названных теорий, моделей и гипотез применительно к взрослым обучающимся является следующее. Всякий параметр воспринимаемого образа фиксируется в многомерном пространстве перцептивных категорий. Сложность перцептивного материала аналогична количеству признаков его кодировки. Образный код более применим к 
конкретной, нежели к абстрактной информации. Он осуществляет параллельную обработку информации, а символический код - последовательную. Знания (понятия) сгруппированы по категориальным и атрибутивным признакам и основаниям, а также по существенным и второстепенным признакам. Базовой когнитивной структурой является концепт, который задается дефиницией (определением), связывает смысл и значение со знаком (словом), фиксирует характеристики определенного множества предметов. Концепты подвержены иерархии. Элементы семантических сетей выстраиваются в устойчивые когнитивные образования - схемы выполнения определенного множества аналогичных операций. Такие схемы являются блоками организации знаний, они образуют неделимые и восстановимые в памяти единицы, которые автономны относительно других знаний.

Представителями деятельностного подхода (А.Н.Леонтьев, П.И.Зинченко, А.А.Смирнов, В.Я.Ляудис и др.) определены закономерности процесса запоминания. В процессе познания реализуется непроизвольное и произвольное запоминание при опережении первого. Непроизвольному запоминанию взрослых способствуют следующие факторы: глубина понимания и обусловленная ею интеллектуальная активность, целенаправленные действия, продукт собственной деятельности, осложненный препятствиями продукт, высокая деятельностная активность. Оптимизирующими факторами произвольного запоминания являются его мотивация, целеполагание, направленность мнемических действий: глубина понимания заучиваемого, последовательность, точность и полнота воспроизведения и др. В основе произвольности запоминания (заучивания) взрослыми обучающимися: ясность и конкретность целей, активная мыслительная деятельность, специальные мыслительные действия (смысловая группировка материала, выделение смысловых опорных пунктов, составление плана, смысловое соотнесение), сопряжение повторения пройденного с решением новой мыслительной задачи.

В число влияющих на процесс обучения особенностей взрослых обучающихся входят их нацеленность «на себя», возрастная сенситивность 
психофизиологических свойств головного мозга, настроенность на конечный результат в конструктивной деятельности, возрастные кризисы и др. В основе процесса обучения - субъективно-прагматические запросы обучающихся, распространяющиеся на свободу выбора учебныхпредметов. Содержание обучения взрослых по И.А. Колесниковой [15, с. 144] включает формирование научно содержательной картины мира, работу с информационными потоками, общение «человек - человек», «человек - компьютер», «человек - компьютер человек», проектирование, социально-экономическую компетентность, здоровьесбережение, саморазвитие. В аудитории создаются субъект-субъектные отношения с педагогом и благоприятная обучающая среда для формирования у взрослых обучающихся потребности, способности и готовности вести конструктивный диалог, определять маршрут обучения, реализовывать свой креативный потенциал.

Классическими дидактическими принципами со времен Я.-А. Коменского остаются наглядность, постепенность, сознательность, последовательность, прочность, посильность. Используемые нейродидактикой, они дополняются современными научностью, профессиональной направленностью обучения, системностью, самостоятельностью, активностью, а также широко используемыми прагматистами проблемным обучением, включением в него элементов игры, самостоятельностью, вовлечением в социальное окружение. К данному перечню принципов Т.П. Брамелд отнес профессиональноориентированную беседу, наблюдение за окружающей средой, общественнополезный труд, посещение музеев и предприятий и др. [16, p.145-150].

Изложенное выше легло в основу модели нейродидактики взрослых (См. табл. 1)

\section{Таблица 1. Модель нейродидактики взрослых}

\begin{tabular}{|l|l|l|}
\hline № & Этап & Содержание этапа \\
\hline 1. & Мотивирующий & $\begin{array}{l}\text { Рефлексия внутреннего опыта взрослых обучающихся, его } \\
\text { экстериоризация, формирование мотивации на обучение, } \\
\text { выработка его индивидуальной траектории. }\end{array}$ \\
\hline 2. & Диагностический & $\begin{array}{l}\text { Выявление у взрослых обучающихся латеральной асимметрии } \\
\text { полушарий головного мозга, модальности внутреннего опыта } \\
\text { (аудиальной, визуальной, кинестетической), }\end{array}$ \\
\hline
\end{tabular}




\begin{tabular}{|c|c|c|}
\hline & & $\begin{array}{l}\text { психодинамических особенностей (активность, моторика, } \\
\text { эмоциональность), индивидуальной динамики развития } \\
\text { психологических процессов (произвольное внимание, } \\
\text { воображение, мышление, воля и др.), допустимого объема и } \\
\text { скорости обработки информации, преобразующего вида } \\
\text { памяти, гибкости мыслительных процессов, когнитивных } \\
\text { способностей, предпочтительных способов усвоения и } \\
\text { переработки новой информации, дифференцированного } \\
\text { восприятия пространства и времени. }\end{array}$ \\
\hline 3. & $\begin{array}{l}\text { Учебно- } \\
\text { развивающий }\end{array}$ & $\begin{array}{l}\text { Использование автоматизированных умственных действий и их } \\
\text { алгоритмической траектории, обеспечение эмоционального } \\
\text { выражения (оптимизм, успех, радость, интерес, удивление, } \\
\text { высокая самооценка) побудительной и оценочной функций } \\
\text { познавательной деятельности, или связи «интеллекта» с } \\
\text { «аффектом». Развитие эмоционального интеллекта (EQ) } \\
\text { посредством создания в группе взрослых обучающихся } \\
\text { атмосферы творчества, успешности, свободы самовыражения. } \\
\text { Стимулирование «категориального» мышления и поведения } \\
\text { посредством речевого смысловыражения,общения. } \\
\text { Акцентуация внимания обучающихся на выборе точных слов, } \\
\text { терминологической точности, грамотном оформлении речи. } \\
\text { Использование профессиональных компетенций в обучении. } \\
\text { Учет полоролевой дифференциации и личностной } \\
\text { идентичности.Рефлексия, уточнение мотивов, развитие } \\
\text { самосознания. }\end{array}$ \\
\hline 4. & Методический & $\begin{array}{l}\text { Соблюдение педагогом логики, системности, предвосхищения } \\
\text { в презентации и усвоении учебной информации. Паритетное } \\
\text { оперирование визуально-пространственной памятью и } \\
\text { заучиванием. Использование индукции и дедукции, анализа и } \\
\text { синтеза, конкретизации и обобщения в подаче нового учебного } \\
\text { материала. Поддерживающее развитие когнитивной сферы } \\
\text { взрослых посредством соответствующих принципов, методов, } \\
\text { форм. }\end{array}$ \\
\hline 5. & Контролирующий & $\begin{array}{l}\text { Контроль эффективности индивидуальной траектории } \\
\text { обучения. }\end{array}$ \\
\hline
\end{tabular}

Если первые три этапа рассмотрены нами достаточно подробно, то последующие два - методический и контролирующий - сопроводим комментариями. Многообразие нейро- физиологических и психологических проявлений взрослых обучающихся влечет за собой богатый набор форм учебной работы: индивидуальные образовательные траектории и маршруты, корпоративное обучение, групповое проектирование, сетевые обучающие программы, информационно-коммуникационные технологии, самообразование. Современные средства связи (кабельное и спутниковое телевидение, модемная и 
оптоволоконная связь), гипермедиа технологии создают условия для обучения взрослых на дому. Эффективными формами дистанционного обучения являются телефонный «тьюторинг», видео-курсы, радио- и видео- конференции, интерактивные обучающие программы, корреспондент-обучение с использованием электронной почты, сетевые проекты и др. Учебный материал помещается и распространяется на компакт- и лазерных дисках, в базах данных, мультимедийных учебниках, образовательных порталах, банках обучающих программ и др.

Продуктивные методы обучения по Г.М. Коджаспировой и А.Ю. Коджаспирову [17, с.180-181] охватывают: визуальные (наблюдение), устные (опрос индивидуальный, уплотненный, фронтальный), письменные (тестирование, диктанты, эссе, письменные работы, рефераты), практические, или лабораторные (практические работы, опыты), программированные (машинные, безмашинные), графические (схемы, графики, таблицы), самоконтроль и др. Этот перечень дополним предлагаемыми Ю.К. Бабанским [18, с. 14] методами индуктивными и дедуктивными, словесными (лекция, беседа, рассказ, объяснение, конференция, дискуссия), наглядными (демонстрация, иллюстрация), практическими (практические задания, упражнения), проблемно-поисковыми, репродуктивными, самостоятельной работой, проектированием. Особо подчеркнем методы когнитивного профессионального обучения взрослых: конструктивное обучение, когнитивное инструктирование, направляющие тесты и вопросы, имитационное планирование, проблемно-развивающий, экспериментальное учение. Хорошо зарекомендовали себя методы интерактивные (ролевые, имитационные, деловые), организационные, тренинги, «кейс-стади». Качество мозговых процессов планирования, структурирования, прогнозирования улучшается благодаря организационным методам систематизации, программирования, планирования, прогнозирования, контроля, рефлексии, партнерства, сотрудничества, коллегиальности. 
Названные выше дидактические, когнитивные, организационные методы насыщают занятие интеллектуально и эмоционально, стимулируют работу высших психических функций, мыслительную активность взрослых обучающихся, инициируют когнитивную перестройку сознания.

Конечным этапом моделируемого обучения взрослых выступает контрольный. Он представлен промежуточной и итоговой диагностикой, коррекцией нейродидактического профиля, рефлексией, планированием последующего развития в изучаемой области. Методы промежуточной диагностикивключают анализ социальных и профессиональных ситуаций, групповые дискуссии, мониторинг развития, диагностические семинарытренинги. Последние включают тренинги интеллектуальных умений, логического мышления, делового и партнерского общения, аргументации, внимания, наблюдательности и др. Итоговая диагностика задается виртуальной реструктуризацией социально-профессиональной жизни, проектированием сценариев профессионального роста, рефлексией достижений.

\section{Библиографический список:}

1. Ермолаева М.Г. Эскиз рассуждения о понятии взрослость. СПБ.: Экспресс, 2004.

2. Змеёв С.И. Андрагогика: основы теории, истории и технологии обучения взрослых. М. 2007.

3. Мальсагов АА., Лезина В.В. Нейродидактикавзрслых. Пятигорск: ПГУ, 2017,185 c.

4. Лурия А.Р. Мозг человека и психические процессы. М.: Педагогика, 1970. T.2.

5. Леонтьев А.Н. Потребности, мотивы, эмоции. М.: МГУ, 1971.

6. Выготский Л.С. Учение об эмоциях. Историко-психологическое исследование // Собр. соч.: в 6 т. М.: Педагогика, 1984. Т. 6.

7. Вилюнас В.К. Психология эмоциональных явлений. М.: МГУ, 1976.

8. Рубинштейн С.Л. Основы общей психологии: В 2 т. СПб.: Питер, 2002. 
9. Выготский Л.С. Проблема эмоций // Вопросы психологии, 1958. № 3.

10. Божович Л.И. Проблемы формирования личности // Изб. Психол. труды. М.-Воронеж: МОДЭК, 1995. Т. 4.

11. Зденек М. Развитие правого полушария. Минск: Попурр, 1997.

12. Thurstone L.L. Vectors of Mind: Multiple-factor Analysis for the Isolation of Primary Traits. Chicago, 1935.

13. GuilfordI. P. Personality. N.Y. 1959.

14. Маланов С.В. Методологические и теоретические основы психологии: учеб. пособие. М.: МПСИ; Воронеж: НПО «МОДЭК», 2005.

15. И.А. Колесникова. Педагогическое проектирование : учеб. пособие для высш. учеб. заведений. М.: Академия, 2007.

16. Brameld T. Toward a Reconstructed Philosophy of education. N.Y.Dryden Press. Inc., 1956.

17. Коджаспирова Г.М., Коджаспиров А.Ю. Словарь по педагогике. М.:ИКЦ «МарТ», Ростов н/Д: Изд. центр «МарТ», 2005

18. Бабанский Ю.К. Оптимизация учебно-воспитательного процесса. М.: Просвещение, 1982. 